\title{
The significance of expression of Her2neu in squamous cell carcinoma of uterine cervix
}

\author{
Shakti Kumar Yadav, Alekh Verma, Sompal Singh, Namrata Sarin*
}

Department of Pathology, North Delhi Municipal Corporation Medical College and Hindu Rao Hospital, New Delhi, India

Received: 05 June 2019

Accepted: 02 July 2019

*Correspondence:

Dr. Namrata Sarin,

E-mail: drnamrata50@gmail.com

Copyright: (c) the author(s), publisher and licensee Medip Academy. This is an open-access article distributed under the terms of the Creative Commons Attribution Non-Commercial License, which permits unrestricted non-commercial use, distribution, and reproduction in any medium, provided the original work is properly cited.

\begin{abstract}
Background: Cervical cancer is one of the leading causes of cancer related deaths among females. It arises from precursor lesions i.e. squamous intraepithelial lesions which are closely associated with infection by HPV. The ERBB2 protooncogene encodes for a cellular transmembrane protein (erb-b2) which has tyrosine kinase activity and has been implicated in the regulation of cellular growth and proliferation in various cancers. Application of monoclonal antibodies against Her2neu has shown higher response and improved survival. The aim of the study was to evaluate the expression of Her2neu in squamous cell carcinoma of cervix in relation to tumor characteristics and to compare the expression with normal control subjects.

Methods: It was a cross-sectional analytical study. Paraffin embedded tissue blocks from 30 cases of squamous cell carcinoma were obtained from the archives. Twenty age matched cases of normal cervix removed for lesions other than that related to cervix (like leiomyoma) were taken as control. Tumour characteristics were noted from the records. Her2neu immunostaining was done. Her2neu expression was scored as positive or negative according to the American Society of Clinical Oncology and the College of American Pathologists (ASCO/CAP) scoring system for Her2neu. The Chi-square test was used to compare and find association between the variables. Student t-test was used to compare the variable between cases and controls.

Results: Her2neu was positive in $20 \%$ and negative in $80 \%$ cases of the study group. Her2neu positivity is not associated with size, histological grade and FIGO stage of the tumor. We found that all Her2neu positive cases showed no lymph node metastasis. This association between Her2neu positivity and lymph node status was statistically significant.

Conclusions: Her2neu immunoexpression is variable across various categories of squamous cell carcinoma. Her2neu positivity might be negatively associated with lymph node metastasis. However, a more comprehensive study encompassing various factors related to Her2neu overexpression is required to validate these results.
\end{abstract}

Keywords: Carcinoma, Cervix, ERBB2, Herceptin, Her2neu, Squamous

\section{INTRODUCTION}

Cervical cancer is one of the commonest cause of cancer related deaths among women in developing countries. ${ }^{1}$ Today, majority of women dying from cervical cancer live in developing countries like India. ${ }^{2}$ Although cervical cancer is curable in early stages, the prognosis for advanced stage disease is poor. ${ }^{3}$

Cervical cancers arise from precursor lesions i.e. squamous intraepithelial lesions which is closely associated with infection by HPV subtypes 16, 18, 31, 13, 
33 and 51. Genetic alterations like abnormal expression of oncoproteins may play a key role in the pathogenesis of this tumor. Study of these oncoproteins may offer target for potential anticancer therapies. ${ }^{4}$

The protooncogene ERBB2 (formerly c-erb-B2 or Her2neu) is located on chromosome 17 at $17 \mathrm{q} 11.2-\mathrm{q} 12$ and encodes for a cellular transmembrane protein (erbb2) which has a molecular weight of $185 \mathrm{kD}$. It has tyrosine kinase activity and has been implicated in the regulation of cellular growth and proliferation. ${ }^{4,5}$ The activating alteration of ERBB2 gene which lead to human cancer is gene amplification leading to overexpression of Her2neu oncoprotein. ${ }^{4}$

Current standard of cancer therapy is receptor-mediated tumor targeted radiotherapy and chemotherapy, which is based on the delivery of therapeutically relevant drugs directly to disseminated tumor cells, with hopefully minimal damage to normal tissues. The presence of Her2neu receptors have been associated with accelerated tumor progression and therapeutic resistance for several types of malignancies viz breast and gastric carcinoma. Application of Trastuzumab drug, which is a humanized monoclonal antibody has shown higher response and improved survival. ${ }^{4}$ The causal relationship of Her2neu receptor network to disease progression and resistance to therapy may provide a rationale for therapeutic intervention. ${ }^{6}$

The present study was carried out with the aim to evaluate the expression of Her2neu in squamous cell carcinoma of cervix in relation to tumor characteristics and to compare the expression with normal control subjects.

\section{METHODS}

The study was conducted over period of one year (March 2014 to March 2015). All the consecutive total hysterectomy cases of squamous cell carcinoma of the uterine cervix were included in the study. Squamous cell carcinoma diagnosed on cervical punch biopsy or cervical conisation surgery were excluded from the study group. Paraffin embedded tissue blocks from selected 30 cases with squamous cell carcinoma were obtained. For control group 20 age matched cases of normal cervix removed for lesions other than that related to cervix (like leiomyoma) were taken. Cervix with feature of chronic cervicitis or any dysplasias were excluded from the study. Clinical details of the patients were retrieved from the records. Clinical staging of the tumor cases was done using the International Federation of Gynecology and Obstetrics (FIGO) staging system for cervical tumors. ${ }^{2}$

Sections were stained by haematoxylin and eosin staining for histological examination. Squamous cell carcinoma cases were graded as per the modified Broder system on the basis of keratinization, cellular atypia and mitotic activity into well-differentiated, moderately differentiated and poorly differentiated squamous cell carcinoma (Figure 1). ${ }^{2}$

Immunohistochemical staining was done on 5- $\mu \mathrm{m}$ tissue sections taken on poly-L-lysine coated slides. Her2neu immunostaining was done using polymer-HRP (Horseraddish peroxidase) detection kit, (Biogenex, USA). Section from previously reported case of carcinoma breast with positive expression of Her2neu was used as control. Her2neu expression was scored as positive or negative based on the American Society of Clinical Oncology and the College of American Pathologists (ASCO/CAP) scoring system for Her2neu. ${ }^{7}$ The Chisquare test was used to compare and find association between the variables. Student t-test was used to compare the variable between cases and controls. Statistical analysis was done using the IBM SPSS 23 (IBM, Armonk, NY, USA) software and a $\mathrm{p}$ value of $<0.05$ was considered significant.

\section{RESULTS}

The mean age of the study group was $48.13 \pm 7.81$ years and that of control group was $44.00 \pm 7.52$ years.

Distribution of cases according to tumor characteristics is shown in Table 1 . The tumor size was $<4 \mathrm{~cm}$ among $53.3 \%$ and $>4 \mathrm{~cm} 46.6 \%$ of the cases. Moderate tumor grade was observed among $66.7 \%$ of the cases. The lymph node metastasis was present in $46.5 \%$ of the cases. FIGO stage IB 1 was seen in $53.3 \%$ of the cases.

Table 1: Distribution of cases according to tumor characteristics.

\begin{tabular}{|ll|}
\hline Tumor characteristics & Number $(\%)$ \\
\hline \multicolumn{1}{|l|}{ Tumor size in cms } & $16(53.3)$ \\
\hline$<4$ & $14(46.6)$ \\
\hline$>4$ & \\
\hline Tumor grade & $4(13.3)$ \\
\hline Well differentiated & $20(66.7)$ \\
\hline Moderate & $6(20.0)$ \\
\hline Poor & \\
\hline Lymph node Metastasis & $10(33.3)$ \\
\hline Positive & $20(66.7)$ \\
\hline Negative & \\
\hline TNM stage & $16(53.3)$ \\
\hline T1b1 N0 M0 & $4(13.3)$ \\
\hline T1b2 N0 Mx & $10(33.3)$ \\
\hline T1b2 N1 Mx & \\
\hline FIGO stage & $16(53.3)$ \\
\hline IB1 & $4(13.3)$ \\
\hline IB2 & $10(33.3)$ \\
\hline IIIB & \\
\hline
\end{tabular}

Her2neu expression was compared between cases and controls (Figure 2 and 3), and it was found to be positive in $23.3 \%$ of tumor and negative in $76.6 \%$ cases of the 
study group, while Her2neu was positive in $15 \%$ and negative in $85 \%$ of the controls. This difference in expression of Her2neu between cases and controls was statistically insignificant ( $\mathrm{p}$ value 0.46 ).

Table 2: Comparison of HER2neu expression with tumor size and grade.

\begin{tabular}{|llll|}
\hline \multirow{2}{*}{ HER2neu expression } & \multicolumn{2}{l|}{ Tumor Sive } & p- \\
\cline { 2 - 3 } & $<\mathbf{4} \mathbf{~ c m}$ & $\mathbf{>} \mathbf{4 c m}$ & value $^{1}$ \\
\hline Positive $(n=7)$ & 5 & 2 & \multirow{2}{*}{0.27} \\
\hline Negative $(n=23)$ & 11 & 12 & \\
\hline
\end{tabular}

${ }^{1}$ Chi-square test

Among the study group, correlation of tumor size, tumor grade, lymph node status and FIGO stage with expression of Her2neu was done. We did not find any association of HER2neu with size and grade of the tumor (Table 2 and $3)$.

Table 3: Comparison of HER2neu expression with histological grade.

\begin{tabular}{|lllll|}
\hline HIER2neu & \multicolumn{3}{l|}{ Histological grade } & p- \\
\cline { 2 - 4 } expression & Well & Moderate & Poor & value $^{1}$ \\
\hline Positive $(n=7)$ & 2 & 5 & 0 & \\
\cline { 1 - 4 } Negative $(n=23)$ & 2 & 15 & 6 & 0.17 \\
\hline
\end{tabular}

${ }^{1}$ Chi-square test

Out of the Her2neu positive cases in study group, majority $(71.4 \%)$ were in stage IB1. While, out of the Her2neu negative cases $47.8 \%$ were in stage IB1 and $43.4 \%$ were in stage IIIB. However, this difference in distribution of the cases was statistically not significant. Her2neu expression was not found to be associated with the FIGO stage (Table 4).

Table 4: Comparison of FIGO stage with HER2neu expression.

\begin{tabular}{|c|c|c|c|c|}
\hline \multirow{2}{*}{$\begin{array}{l}\text { HER2neu } \\
\text { expression }\end{array}$} & \multicolumn{3}{|c|}{ FIGO stage } & \multirow{2}{*}{$\begin{array}{l}\text { p- } \\
\text { value }^{1}\end{array}$} \\
\hline & IB1 & IB2 & IIIB & \\
\hline Positive (n=7) & 5 & 2 & 0 & \multirow{2}{*}{0.07} \\
\hline Negative $(n=23)$ & 11 & 2 & 10 & \\
\hline
\end{tabular}

${ }^{1}$ Chi-square test

Table 5: Comparison of HER2neu expression scores according to lymph node metastasis.

\begin{tabular}{|llll|}
\hline HER2neu & \multicolumn{2}{l|}{ Lymph node metastasis } & p- \\
expression & Present & Absent & value $^{1}$ \\
\hline Positive $(n=7)$ & 0 & 7 & \multirow{2}{*}{0.021} \\
\hline Negative $(n=23)$ & 10 & 13 & \\
\hline
\end{tabular}

${ }^{1}$ Chi-square test

Lymph node metastasis was present in 10 (33.3\%) cases while $20(66.6 \%)$ were negative. None of the cases with lymph node metastasis showed Her2neu positivity. However, out of 20 cases without lymph node metastasis
7 cases showed positive Her2neu expression. We found that Her2neu positivity was associated with status of lymph node metastasis (Table 5).

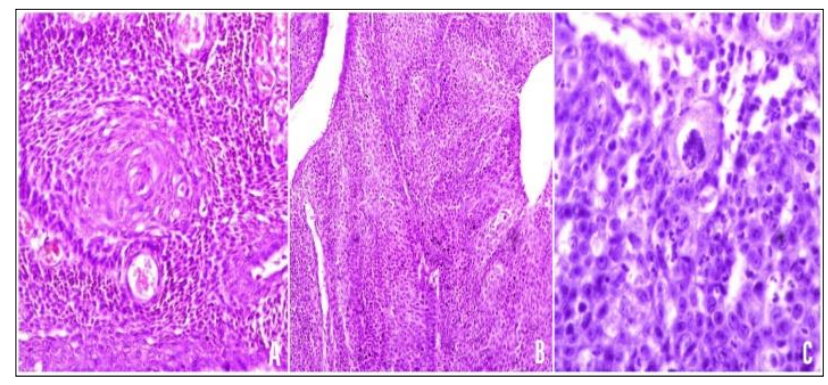

Figure 1: Photomicrograph showing well differentiated (A, H and E, 400x), moderately differentiated $(B, H$ and $E, 100 x)$ and poorly differentiated $(\mathrm{C}, \mathrm{H}$ and $\mathrm{E}, \mathbf{4 0 0 x})$ squamous cell carcinoma of uterine cervix.

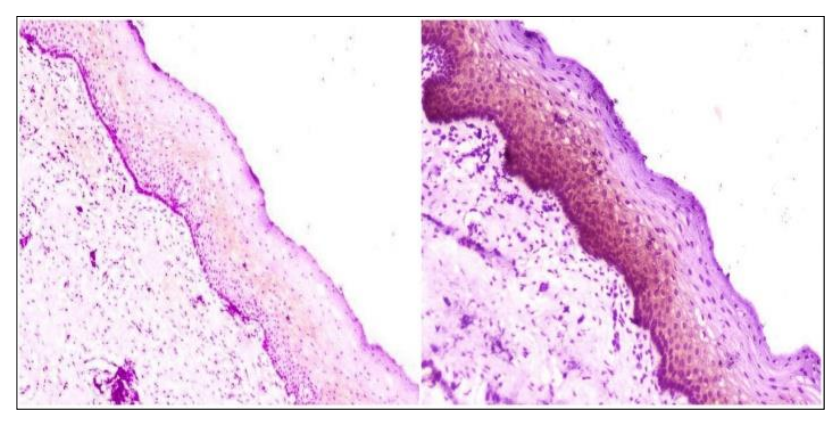

Figure 2: Photomicrograph showing Her2neu staining in normal cervical epithelium A: negative Her2neu staining, B: Positive Her2neu staining (DAB, 100x).

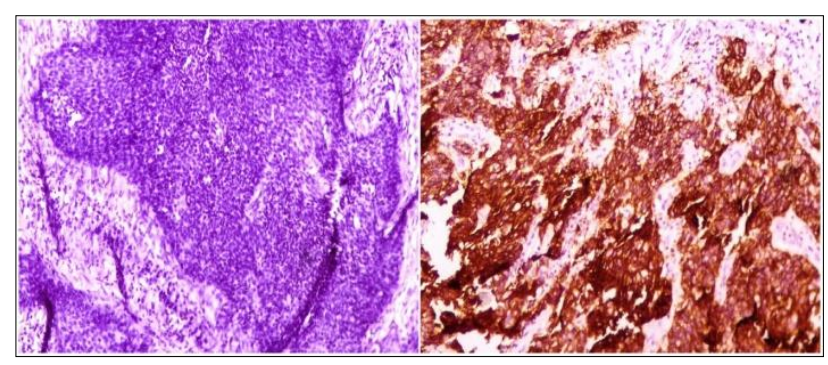

Figure 3: Photomicrograph showing Her2neu staining in moderately differentiated squamous cell carcinoma of uterine cervix A: negative Her2neu staining, B: Positive Her2neu staining (DAB, 100x).

\section{DISCUSSION}

Cervical cancer is one of the most prevalent cancers among Indian females and is a significant cause of morbidity and mortality among women. ${ }^{8}$ Presently, oncogene ERBB2 is thought to be related with various malignant lesions viz. breast and gastrointestinal cancers. ${ }^{9}$ Mutation in ERBB2 gene leads to the overexpression of the Her2neu oncoprotein, which makes the basis of detection by immunohistochemistry. ${ }^{10}$ Many 
studies have shown that, this oncogene may serve as excellent target for the development of anti-cancer drugs against ERBB2 expression. ${ }^{11}$

In the available literature on expression of Her2neu in carcinoma of cervix, there are conflicting results. Present study was done to compare the expression of Her2neu oncoprotein using immunohistochemistry in of squamous cell carcinoma cervix and to find its correlation with the various prognostic factors. In our study, Her2neu expression was positive in $23.3 \%$ cases in the study group, while it was negative in the $76.6 \%$ cases. In the control group, the cervical epithelium shows Her2neu immunoexpression in the $15 \%$ cases, while it was negative in $85 \%$ controls. Similar to our study, in the study by Rosty et al. ${ }^{12}$ There was positive immunolabelling in $29 \%$ of the tumor cases, while $71 \%$ cases were found to be negative in Her2neu expression.

In a study by Califano et al. ${ }^{4}$ Her2neu staining was positive in $38 \%$ cases of squamous cell carcinoma. Chavez-Blanco et al. ${ }^{13}$ showed that only 1 out of 35 cervical cancer cases showed Her2neu overexpression. They also found that two out of four recurrent tumors that were negative at the time of primary diagnosis became Her2neu positive. Gupta et al, found increased expression of Her2neu in $63 \%$ cases of cervical cancers, however only $24 \%$ (18 out of 75 ) cases having $3+$ intensity could be labelled as positive for overexpression. ${ }^{14}$ In concordance to present study, they also found that $29 \%$ (14/48) cases of squamous cell carcinoma had $3+$ positivity for He2neu. Nevin et al, found that $45.5 \%$ cases of squamous cell carcinoma were positive for Her2neu overexpression. ${ }^{5}$

In present study, we also compared the Her2neu immuno expression with various tumor characteristics and prognostic factors like size, nodal metastasis and FIGO stage.

We found correlation between Her2neu expression and FIGO stage of the tumor. We found that Her2neu immunoexpression was more prominent in early stages of the tumor than in advanced stage. Similar to our findings, Califano et al, found higher expression of Her2neu in stage I and II as compared to more advanced stages, only $14 \%$ cases of stage III and no case in stage IV showed Her2neu overexpression. ${ }^{4}$ In contrast to our study, Gupta et al, found significant correlation between Her2neu expression and higher clinical stage. ${ }^{14}$ This may be due different relative proportion of early stage tumors than advanced stage tumors.

In present study, we found that the Her2neu expression was negative in all cases with nodal metastasis. However in contrast to our finding, Gupta et al, found significantly higher expression of Her2neu in tumors with nodal metastasis. ${ }^{14}$ They found that out of 11 cases with nodal metastasis $90.9 \%$ were Her2neu positive, while out of 26 node negative cases, only $34.6 \%$ were positive for
Her2neu expression. Nevin et al, found that Her2neu expression was positive in $45.5 \%$ cases of squamous cell carcinoma with nodal metastasis, while only $35.6 \%$ node negative cases showed Her2neu positivity. ${ }^{5}$ They also found that $16.7 \%$ cases node positive adenosquamous carcinoma and $100 \%$ cases of node positive adenocarcinoma showed positive Her2neu expression.

We did not find any correlation of Her2neu expression with tumor size and tumor grade. These finding were in concordance with the findings of Califano et al. ${ }^{4}$ However, Gupta et al, found that Her2neu expression was significantly higher in moderately and poorly differentiated tumors than well differentiated tumors. ${ }^{14}$ This difference in the result might be due to heterogenicity of tumors of some technical problem in antigen retrieval in some higher grade tumor.

The present study, suggests that a good number of cases of squamous cell carcinoma of cervix show Her2neu overexpression and availability of targeted monoclonal antibody cancer therapy against Her2neu i.e. trastuzumab may potentially be used against tumors with its overexpression.

The findings of present study might be limited by its small sample size; however, it is suggested that a more extensive study having a larger sample size might be needed to validate the findings of present study.

\section{CONCLUSION}

In conclusion, present study suggests that Her2neu immunoexpression is variable across various categories of squamous cell carcinoma of uterine cervix. Her2neu positivity might be negatively associated with lymph node metastasis. However, a more comprehensive study encompassing various factors related to Her2neu overexpression is required to validate these results.

\section{Funding: No funding sources}

Conflict of interest: None declared

Ethical approval: The study was approved by the Institutional Ethics Committee

\section{REFERENCES}

1. Denny L. Cervical cancer: prevention and treatment. Discov Med. 2012;14:125-31.

2. Wells M, Ostor AG, Franceschi S, et al. Epithelial tumors. In: Tavassoli FA, Devilee P, eds. Tumors of the breast and female genital organs. Lyons, France: IARC Press; 2003;262-79.

3. Long HJ, Bundy BN, Grendys EC, Jr., Benda JA, McMeekin DS, Sorosky J, et al. Randomized phase III trial of cisplatin with or without topotecan in carcinoma of the uterine cervix: a Gynecologic Oncology Group Study. J Clin Oncol. 2005;23:4626-33. 
4. Califano D, Losito S, Pisano C, Santelli G, Greggi $\mathrm{S}$, Iodice $\mathrm{F}$, et al. Significance of erb-B2 immunoreactivity in cervical cancer. Front Biosci. 2006;11:2071-6.

5. Nevin J, Laing D, Kaye P, McCulloch T, Barnard R, Silcocks $P$, et al. The significance of Erb-b2 immunostaining in cervical cancer. Gynecol Oncol. 1999;73:354-8.

6. Shen L, Shui Y, Wang X, Sheng L, Yang Z, Xue D, et al. EGFR and HER2 expression in primary cervical cancers and corresponding lymph node metastases: implications for targeted radiotherapy. BMC Cancer. 2008;8:232.

7. Wolff AC, Hammond MEH, Hicks DG, Dowsett M, McShane LM, Allison KH, et al. Recommendations for human epidermal growth factor receptor 2 testing in breast cancer: American Society of Clinical Oncology/College of American Pathologists clinical practice guideline update. Archives of Pathology and Laboratory Medicine. 2013;138:241-56.

8. Shanta V, Krishnamurthi S, Gajalakshmi CK, Swaminathan R, Ravichandran K. Epidemiology of cancer of the cervix: global and national perspective. J Indian Med Assoc. 2000;98:49-52.

9. Cirisano FD, Karlan BY. The role of the HER-2/neu oncogene in gynecologic cancers. J Soc Gynecol Investig. 1996;3:99-105.
10. Borg A, Tandon AK, Sigurdsson H, Clark GM, Ferno M, Fuqua SA, et al. HER-2/neu amplification predicts poor survival in node-positive breast cancer. Cancer Res. 1990;50:4332-7.

11. Hung MC, Lau YK. Basic science of HER-2/neu: a review. Semin Oncol. 1999;26:51-9.

12. Rosty C, Couturier J, Vincent-Salomon A, Genin P, Freneaux P, Sigal-Zafrani B, et al. Overexpression/amplification of HER-2/neu is uncommon in invasive carcinoma of the uterine cervix. Int J Gynecol Pathol. 2004;23:13-7.

13. Chavez-Blanco A, Perez-Sanchez V, GonzalezFierro A, Vela-Chavez T, Candelaria M, Cetina L, et al. HER2 expression in cervical cancer as a potential therapeutic target. BMC Cancer. 2004;4:59.

14. Gupta N, Singh S, Marwah N, Kumar S, Chabra S, Sen R. HER-2/neu expression in lesions of uterine cervix: is it reliable and consistent? Indian J Pathol Microbiol. 2009;52:482-5.

Cite this article as: Yadav SK, Verma A, Singh S, Sarin N. The significance of expression of Her2neu in squamous cell carcinoma of uterine cervix. Int $\mathbf{J}$ Reprod Contracept Obstet Gynecol 2019;8:3250-4. 